\title{
EFEITOS DA INTERVENÇÃO ASSISTIDA POR ANIMAIS EM CRIANÇAS HOSPITALIZADAS: CONTEÚDOS PSÍQUICOS
}

\section{ARTIGO ORIGINAL}

FACCIN, Annelisa Bruna ${ }^{1}$

CUNHA, Maria Claudia ${ }^{2}$

FACCIN, Annelisa Bruna. CUNHA, Maria Claudia. Efeitos da intervenção assistida por animais em crianças hospitalizadas: Conteúdos psíquicos. Revista Científica Multidisciplinar Núcleo do Conhecimento. Ano 05, Ed. 08, Vol. 06, pp. 15-36. Agosto de 2020. ISSN: 2448-0959, Link de acesso: https://www.nucleodoconhecimento.com.br/psicologia/criancas$\underline{\text { hospitalizadas }}$

\section{RESUMO}

Introdução: Intervenção Assistida por Animais (IAA) é toda atividade que incorpora animais aos campos da saúde e educação visando ganhos terapêuticos em humanos. Com pacientes pediátricos hospitalizados, estudos sugerem benefícios da interação da criança e animal. Objetivo: Avaliar os efeitos da IAA na expressão verbal e não verbal de conteúdos psíquicos em crianças hospitalizadas. Método: Pesquisa qualitativa baseada em estudo de casos de 05 sujeitos (02 do sexo masculino e 03 do feminino), faixa etária entre 06 e 10 anos, hospitalizados há pelo menos 02 dias. Cães co-terapeutas: Thor, 04 anos e Kate, 03 anos, da raça Golden Retriever, selecionados de acordo com critérios de protocolos internacionais e conduzidos pela pesquisadora.

\footnotetext{
${ }^{1}$ Mestrado em Fonoaudiologia pela Pontifícia Universidade Católica de São Paulo; Psicóloga.

2 Doutorado em Psicologia Clínica pela Pontifícia Universidade Católica de São Paulo. Professora titular do Departamento de Clínica Fonoaudiológica da Faculdade de Ciências Humanas e da Saúde da Pontifícia Universidade Católica de São Paulo.
} 
Foram aplicados desenhos livres e teste Wartegg, pré e pós IAA. Resultados: a presença do cão favoreceu maior contato com conteúdos emocionais associados às tentativas de enfrentamento da doença. Conclusão: IAA no ambiente hospitalar proporcionou, aos sujeitos estudados, a possibilidade de estancar a condição patológica em favor da experiência de reintegração do Eu, ou seja, uma reapropriação de sua identidade subjetiva, parcialmente tolhida pelo processo de adoecimento e hospitalização.

Palavras-chave: Terapia assistida por animais, saúde da criança, técnicas projetivas.

\section{INTRODUÇÃO}

A hospitalização infantil e suas consequências é tema abordado por estudiosos de diversas áreas como a psicologia, enfermagem e educação (COSTA; MORAIS, 2017).

Em 1946, o médico psiquiatra Rene Spitz criou o termo hospitalismo para designar o conjunto de sintomas desenvolvidos por bebês internados em instituições de longa permanência (asilos e hospitais) com privação do contato parental, no período pósguerra. Embora recebessem cuidados físicos, o autor identificou que a ausência de investimento afetivo tornava essas crianças apáticas, inapetentes, deprimidas, com atraso no desenvolvimento motor e de linguagem, e em alguns casos, as levava à morte (LAPLANCHE, 2001).

Ainda hoje, o processo de adoecimento e hospitalização com os quais a criança se depara, excluem suas atividades cotidianas além de outras restrições, podendo causar-Ihe sofrimento (VASQUES; BOUSSO; MENDES-CASTILLO, 2011; MORAES; ENUMO, 2008).

Nessa perspectiva, a hospitalização na infância, além de privar a criança do ambiente familiar, promove um confronto com a dor, limitação física e passividade, aflorando sentimento de culpa, punição e medo da morte (MITRE; GOMES, 2004; SILVA; RIBEIRO, 2000). 
Diante das dificuldades em lidar com a situação de hospitalização, é essencial a utilização de métodos que abrandem a insegurança e o medo por meio do atendimento humanizado, que contemple cuidados com o corpo e o psiquismo (OLIVEIRA; SILVESTRO, 2015; OLIVEIRA; ICHITANI; CUNHA, 2016).

Atualmente, as IAA (Intervenções Assistidas por Animais) em hospitais se inserem na proposta de humanização hospitalar (ICHITANI; CUNHA, 2016), mas já nos anos 50/60, há registros da atuação da psiquiatra Nise da Silveira incluindo cães e gatos (os quais nomeou como coterapeutas) no tratamento de pacientes esquizofrênicos, na medida em que constatou que o convívio com esses animais contribuía, entre outros benefícios, para a retomada do contato desses sujeitos com a realidade externa (DOTTI, 2005).

As IAA, termo definido pela International Association of Human-Animal Interaction Organizations (IAHAIO), referem-se a atividades que incorporam animais aos campos da saúde e educação visando ganhos terapêuticos em humanos (IAHAIO, 2014).

Pesquisas internacionais sugerem que os efeitos positivos da IAA incluem: aumento do bem-estar e conforto em crianças hospitalizadas (CAPRILLI; MESSERI, 2006); redução de estresse em crianças com Transtorno do Espectro Autista (REED; FERRES; VILLEGAS, 2012); modificação na percepção de dor e aceleração da recuperação em crianças no período pós-operatório (CALCATERRA; VEGGIOTTI; PALESTRINI; et al., 2015); diminuição nos níveis de estresse durante os procedimentos de punção venosa em crianças hospitalizadas, sugerindo que a presença do cão induz à sensação de bem-estar do paciente (VAGNOLI; CAPRILLI; VERNUCCl; et al., 2015).

No Brasil, estudos desenvolvidos no contexto hospitalar apontam efeitos favoráveis dessa atividade, tais como: melhora no enfrentamento da doença (BUSSOTTI; LEÃO; CHIMENTÃO; et al., 2005); redução da sensação de dor autorreferida e elaboração de conteúdos emocionais associados à hospitalização (ICHITANI; CUNHA, 2016); contribuição positiva da criança com a enfermagem no processo de quimioterapia (MOREIRA; GUBERT; SABINO; et al., 2016). 
Simultaneamente às pesquisas em IAA, há estudos voltados para o bem estar dos animais co-terapeutas (GLENK; KOTHGASSNER; STETINA; et al., 2014).

O condutor do cão desempenha papel fundamental para o bom desempenho da dupla. Esse condutor deve ser bem treinado, conhecer a espécie e o cão co-terapeuta e manter contato visual e comunicação permanente com o animal durante a intervenção (LEFEBVRE; GOLAB; CHRISTENSEN; et al., 2008).

Os estudos também sugerem que o cão deve ser um animal seguro, calmo, receptivo a estranhos, sociável com outros cães, aceitar com tranquilidade sons altos, vozes ou comportamentos ameaçadores de terceiros, abraços apertados, andar tranquilo na guia e conhecer os comandos básicos (SILVEIRA; SANTOS; LINHARES, 2011).

Ressalta-se que para inserir um programa de visitas de animais em hospitais, devese estabelecer protocolo de higiene e controle de infecções (zoonoses) (LEFEBVRE; GOLAB; CHRISTENSEN; et al., 2008).

Alguns critérios para o atendimento dos pacientes devem ser seguidos: o animal deve ser conduzido na guia nas instalações do hospital; o paciente deve autorizar a visita do animal; evitar a entrada do animal durante as refeições dos pacientes; não permitir lambidas em cateteres e outros equipamentos hospitalares (LEFEBVRE; GOLAB; CHRISTENSEN; et al., 2008). Os pacientes em isolamento podem receber a visita do animal sem que ocorra o contato direto, podendo observar através do visor na porta do quarto (LEFEBVRE; GOLAB; CHRISTENSEN; et al., 2008).

Ainda sobre a hospitalização infantil, é necessário que a criança disponha de recursos psíquicos para elaborar essa experiência (SILVEIRA; SANTOS; LINHARES, 2011). Nessa perspectiva, a brincadeira é uma maneira de a criança expressar seu mundo interno, ou, seja, as fantasias (MITRE; GOMES, 2004). Assim, o brincar é natural e facilita o crescimento, favorecendo os relacionamentos sociais e a saúde (ODENDAAL; MEINTJES, 2003).

A partir dessas considerações, o presente estudo parte da hipótese de que a IAA desenvolvida no ambiente hospitalar instaura um contexto desejavelmente lúdico e 
pode ser um recurso facilitador no processo de elaboração e expressão dos conteúdos psíquicos envolvidos no processo de hospitalização infantil.

Ressalta-se que esta pesquisa investigou a subjetividade infantil nas interfaces entre linguagem, corpo e psiquismo.

\section{OBJETIVO}

Avaliar os efeitos da Intervenção Assistida por Animais na expressão verbal e não verbal de conteúdos psíquicos em crianças hospitalizadas.

\section{MÉTODO}

Trata-se de pesquisa de intervenção de natureza qualitativa.

Este projeto foi aprovado pelo Comitê de Ética da instituição de ensino superior em que foi realizada e do hospital infantil onde foram coletados os dados (protocolo número 65065617.6.3001.5482).

\subsection{CASUÍSTICA}

Sujeitos: 05 crianças, 02 do sexo masculino e 03 do sexo feminino, na faixa etária de 06 a 10 anos, hospitalizadas no setor de internação pediátrica (quartos individuais) de hospital infantil.

A faixa etária foi estabelecida de maneira a abarcar sujeitos que dispunham dos recursos expressivos previstos no procedimento.

Critérios de seleção: crianças internadas há pelo menos 02 dias (a fim de evitar interferências causadas por possíveis transtornos do primeiro dia de hospitalização), com qualquer patologia de base, motivação para o contato com cães e condições físicas que possibilitassem a interação com o animal. A criança deveria estar acordada e consciente, mesmo que não pudesse se deslocar do leito. 
Participaram apenas os sujeitos autorizados pelos pais ou responsáveis, de acordo com assinatura do Termo de Consentimento Livre e Esclarecido e do Termo de Assentimento Livre e Esclarecido.

Local: Ala pediátrica do Hospital Infantil Sabará, São Paulo, SP, referência no atendimento médico hospitalar infantil.

Animais coterapeutas: cão Thor, da raça Golden Retriever, 04 anos; cadela Kate, da raça Golden Retriever, 03 anos. Os cães atuam como coterapeutas desde 2014 participando de visitas em várias instituições (incluindo hospitais); passam por constante avaliação de comportamento e saúde para assegurar a sua própria segurança e a dos assistidos. Os cães foram conduzidos pela pesquisadora.

\subsection{PROCEDIMENTO}

Fase 1: Após a aprovação do projeto pelo hospital, os cães co-terapeutas foram introduzidos no ambiente a fim de se familiarizarem com rotinas, ruídos e odores.

Fase 2: A pesquisadora era informada por uma funcionária do hospital sobre qual sujeito estaria apto a participar da pesquisa. A seguir, entrava em contato por telefone com os pais ou responsáveis pelo sujeito a fim de explicar o objetivo e procedimento da pesquisa. Mediante concordância e autorização do sujeito e dos pais ou responsáveis, o procedimento era iniciado.

Fase 3: A pesquisadora entrava no quarto e explicava o procedimento de coleta de dados à criança. Mediante concordância da criança, o profissional de enfermagem entrava no quarto para medir os batimentos cardíacos, pressão arterial, temperatura corporal e quantidade de oxigênio no sangue (via oxímetro) da criança. Esses dados foram incluídos na descrição da amostra.

Simultaneamente, o cão aguardava no corredor acompanhado pela assistente de pesquisa até que fosse convocado a entrar no quarto. Os dois cães atuavam em dias alternados. 
Em seguida, a pesquisadora fornecia à criança uma folha de papel sulfite e lápis de cor e solicitava à mesma que fizesse um desenho a partir da seguinte instrução: "desenhe como você está se sentindo nesse momento". Finalizado o desenho, era solicitado que a criança fizesse um relato oral sobre o mesmo. Após o relato, foi aplicado o teste de Wartegg: a criança recebia a folha do teste, lápis preto e as instruções verbais para a realização.

A seguir, o cão entrava no quarto, para a realização da IAA por 10 minutos. Sugerese que a partir de 05 minutos de interação com o cão, há um aumento nos níveis dos hormônios como ocitocina e dopamina em humanos (GLENK; KOTHGASSNER; STETINA; et al., 2014). Além disso, a experiência prática com essa atividade demonstra que 10 minutos é um tempo adequado tanto para o bem-estar do cão quanto para o resguardo do sujeito hospitalizado.

A criança podia optar por uma ou mais das seguintes atividades: fazer carinho, escovar, jogar bolinha e/ou dar comandos e petiscos ao cão. Ao final da IAA, o cão saía do quarto e o profissional de enfermagem retornava para repetir a medição dos sinais vitais da criança.

Fase 4: Reaplicação do procedimento acima descrito (desenho, relato oral e teste de Wartegg).

Observação: cada cão realizou apenas 01 IAA por dia, em respeito ao bem-estar animal.

\subsection{CRITÉRIOS DE INTERPRETAÇÃO DOS RESULTADOS}

Análise qualitativa dos dados do desenho e relato oral da criança e dos resultados do teste Wartegg. Os resultados pré e pós IAA foram analisados comparativamente.

Desenho livre: análise descritiva e interpretação dos desenhos pré e pós IAA baseadas nas seguintes categorias: localização no papel que indica o grau de adequação ao meio; pressão e caracterização do traço que indicam o nível de energia; tamanho do desenho que indicam como o sujeito reage às pressões do ambiente, 
cores que indicam a relação com as próprias emoções, conteúdo e variedade de elementos que indicam os aspectos latentes e manifestos do psiquismo (CAMPOS, 2000).

Relato oral: análise comparativa do conteúdo do discurso do sujeito, pré e pós IAA.

Teste de Wartegg: análise e interpretação dos 08 campos do teste pré e pós IAA, baseadas nas categorias estabelecidas no instrumento: campo 1 - o Ego e suas defesas; campo 2 - fantasias, sensibilidade e empatia do sujeito; campo 3 - ambição, aspirações, metas e objetivos do sujeito; campo 4 - como o sujeito lida com a angústia, ansiedade e disforias; campo 5 - como lida com obstáculos, frustrações e problemas; campo 6 - a criatividade e o senso de improvisação; campo 7 características afetivo-emocionais, sensualidade e sexualidade; campo 8 - empatia e relacionamento interpessoal, necessidade de proteger e ser protegido, normas e valores sociais (WARTEGG, 1987).

\section{RESULTADOS}

Não foram observadas alterações nos sinais vitais (temperatura, pressão arterial, frequência cardíaca e oxigênio no sangue) dos sujeitos estudados. Esse dado é sugestivo de questionamento quanto ao procedimento de medição, a saber: tempo de hospitalização dos sujeitos e intervalo de tempo entre as aferições pré e pós IAA.

\section{SUJEITO 01: Idade: 08 anos e 04 meses, diagnóstico: pneumonia.}

DESENHO LIVRE - Pré IAA: Necessidade de se manter focado nos aspectos intelectuais para evitar o contato com os afetos, conflito e dor, como demonstra a escrita predominante na folha. Negação da doença e perda do sentido de eu conforme desenho de um rosto sem corpo e um rosto sem contorno. Relato do sujeito após o desenho: "Fiz uma carinha feliz; to legal e animado." Pós IAA: Maior contato com aspectos emocionais em relação aos racionais, considerando que o desenho foi predominante em comparação com a escrita. Nota-se uma reorganização do Eu, enfrentamento e aceitação da situação vivida considerando que o sujeito se desenhou 
em pé, de frente e de corpo inteiro. O sujeito referenciou o seu desejo de contato com o mundo através da imagem do cão e de sua pelagem que estão voltados para ele. Relato do sujeito após o desenho: "Animado maior que 900 trilhões por cento. O Thor e eu com a bolinha na mão, Thor deitadinho e eu com a bolinha na mão sorrindo". Comparação dos resultados: Redução de manifestação dos conteúdos racionais em favor dos emocionais. Tentativa de equilíbrio e enfrentamento de conflitos. A inserção da figura do cão, e também em cor laranja pode demonstrar que há a possibilidade de contato com o outro. Na comparação do relato do sujeito nota-se que no segundo o mesmo pôde permitir-se brincar e se reapropriar, através do controle da bolinha e do cão "deitadinho", de sua identidade, sem precisar recorrer a aspectos intelectuais de "estar bem", a quantificação dos sentimentos em porcentagens pode estar ligada à necessidade de se manter focado no que é concreto.

WARTEGG - Pré IAA: Ego enfraquecido, susto, percepção positiva do crescimento, tristeza. O momento presente está nublado, o sol representa o momento passado e ele está ilhado, isolamento dos amigos e família. Pós IAA: Eu diluído, perda do contato com o externo, ambiguidade de sentimentos entre estar vivo ou não. Sujeito consegue expressar a sua angústia e no campo 7 , entra em contato com a alegria, apresentando algum aspecto positivo. Comparação dos resultados: Apesar do conflito e angústia da situação vivida, sujeito consegue, no segundo desenho, expressar sentimentos positivos, como por exemplo, o desenho de risadas no campo 7 que leva o título com esse nome e o arco-íris no campo 8.

SÍNTESE FINAL - A presença do cão impactou na redução da racionalização e discurso permeado na necessidade de se apresentar bem e confiante ao mundo e na negação de um corpo doente, favorecendo o contato do sujeito com aspectos emocionais. Foi possível ao sujeito, após a IAA, a simbolização de um corpo, enfrentamento da dor e dar um novo sentido ao conflito, com possibilidade de sentimentos positivos.

SUJEITO 02: Idade: 09 anos, 11 meses, diagnóstico: dor abdominal crônica. 
DESENHO LIVRE - Pré IAA: Desenho sugere racionalização da situação, forte necessidade de proteção do sujeito, inadequação ao ambiente e sua figura, desenhada deitada, expressa sua condição patológica. Relato do sujeito após o desenho: "É horrível, como está escrito. É ruim porque fico levando agulhada, perco as aulas e não tenho amigos. Algumas tias brincam, isso é legal, o parquinho também. Agulha de bebê não dói, mas de adulto... A coberta é bem quentinha". Pós IAA: Racionalização presente pela escrita justificando seu sentimento. Sentimento de insegurança, inibição e inadequação ao meio. Necessidade de identificação demonstrada no desenho do cão voltado de frente para o sujeito e com o rosto apresentando o mesmo desenho do rosto do sujeito. Relato do sujeito após o desenho: "Gostei que a Kate veio. Kate e Apolo tem que se encontrar, vou no casamento deles" (Apolo é um cão terapeuta da mesma raça da Kate que visita o hospital às 6as. Feiras). Comparação dos resultados: O sujeito, antes deitado, agora se apresenta em pé e desenhado de frente para a folha, o que pode indicar uma busca no encorajamento para enfrentar o processo de hospitalização. Há também a transferência da necessidade de proteção de um objeto interno e inanimado (a cama) para um objeto externo e com vida, no caso, o cão. No relato pré IAA percebe-se a necessidade de proteção através da fala "coberta é bem quentinha" e no relato pós IAA a necessidade identificação, já que os dois cães que o sujeito conhece são da mesma raça e precisam e se casar com a presença dela.

WARTEGG - Pré IAA: Sujeito apresenta desejo de contato com o outro e pouco contato com as angústias mais profundas. Sinais de pouca vitalidade e passividade num mundo quadrado e vazio. Necessidade de estar bem perante o mundo. Pós IAA: Autoconfiança e capacidade de ajustar-se ao ambiente. Necessidade de proteção e criatividade para lidar com a crise. Expressão dos sentimentos de medo e contato com o externo. Comparação dos resultados: Apesar da dificuldade de manter o Eu integrado, há mais contato com os conflitos internos e com expressões positivas.

SÍNTESE FINAL - Melhora na capacidade de enfrentar o conflito, maior expressão de sentimentos, como o medo e angústias, e redução dos aspectos racionais. Maior 
adequação ao meio e realização da necessidade de contato com o outro através do cão.

SUJEITO 03: Idade: 09 anos, 04 meses, diagnóstico: dores abdominais.

DESENHO LIVRE - Pré IAA: Desenho sugere racionalização dos sentimentos pela escrita. Baixo nível de energia, inibição e problemas emocionais marcados por traços leves e autoimagem em tamanho pequeno. Por outro lado, o sujeito se mantém em pé e sorrindo, demonstrando necessidade de enfrentamento da situação. O desenho do lado direito da folha em vermelho sugere o desejo do sujeito para o futuro, porém com um rosto não definido e sem contorno que sugere a perda da autoimagem, do sentido de eu. Relato do sujeito após o desenho: "Escrevi feliz porque vão tentar descobrir o que tenho. Eu escrevi bem na barriga ficar com a dor normalizada". Pós IAA: Ainda predomina a necessidade de racionalização pela a escrita na folha, mas com desejo de satisfação de seus impulsos. $O$ desenho do coração vermelho sugere acesso aos aspectos emocionais. Possibilidade de pensar no futuro associada à presença do cão, com o coração desenhado à extrema direita e indicando a presença do animal. Relato do sujeito após o desenho: "Não é que eu tava triste, mas fiquei feliz com o cachorro. Feliz por brincar com o cachorro". Comparação dos resultados: Ainda que o aspecto racional esteja presente no segundo desenho, pode-se notar que o sujeito se permite acessar os conteúdos emocionais e relacionados ao conflito da dor e da hospitalização. No primeiro desenho, mesmo no texto escrito pelo sujeito, nota-se a expressão "ficar feliz", ou seja, ele não está feliz, enquanto no segundo desenho, o verbo "ficar" não aparece. Sugere-se que a presença do cão permitiu a expressão do sentimento do sujeito que estava oculto em seu primeiro desenho por aspectos morais e sentimento de culpa. Comparando os desenhos à direita de ambas as folhas, nota-se que as duas figuras estão em vermelho remetendo aos aspectos emocionais do sujeito e na segunda folha, o rosto aparece com contorno de coração e sem o símbolo médico da cruz, que pode sugerir um desejo de reapropriação do Eu e da libertação da dor da hospitalização. No primeiro relato, percebe-se a necessidade racional de estar bem e com vocabulário atípico para a idade (normalizada). No 
segundo relato, o acesso ao brincar é permitido pelo próprio sujeito, ainda que com ressalvas.

WARTEGG - Pré IAA: Dificuldade para se posicionar frente ao meio, indecisão e medo do contato com o outro. Necessidade de dispersar a angústia. Pouca vitalidade e forte sensibilidade. Necessidade de proteção e aprovação social. Pós IAA: Percepção adequada de si embora com insegurança e dificuldade para ajustar-se ao ambiente. Entrou em contato com a angústia e pôde expressar a agressividade. Buscou respostas criativas para lidar com o conflito. Posicionamento mais crítico e independente. Comparação dos resultados: Sujeito entrou em contato com seu Eu e suas angústias. Deu vazão a sentimentos de agressividade e buscou alternativas internas para lidar com o conflito.

SÍNTESE FINAL - Redução de aspectos racionais e da necessidade de se apresentar bem ao mundo. Maior contato com a afetividade, tentativa de reapropriação do Eu e busca de alternativas internas para lidar com o conflito.

SUJEITO 04: Idade: 06 anos, 11 meses, diagnóstico: colite.

DESENHO LIVRE - Pré IAA: Sentimento de constrição do ambiente, preenchimento de vazio interno e necessidade de contato representados pelo desenho em tamanho excessivamente grande, com riqueza de detalhes e uma janela aberta com céu azul. A condição patológica está presente. Relato do sujeito após o desenho: "O quarto, com a cama, a janela, o relógio, a TV, e tudo que tem aqui. Eu to na cama, feliz". Pós IAA: Sujeito se reposiciona no sofá, buscando alternativa à condição patológica e satisfazendo sua necessidade de contato com o cão. Tentativa de enfrentamento do conflito e reorganização interna. Relato do sujeito após o desenho: "O quarto com a janela, o armário e o sofá. Eu no sofá e o Thor comigo". Comparação dos resultados: Nota-se no segundo desenho maior organização de conteúdos e desaparecimento do excesso de detalhes em relação ao primeiro desenho. Como se todos os detalhes e acessórios estivessem agora dentro do armário e o espaço estivesse mais apropriado à interação do sujeito com o cão. Sugere-se que a presença do cão pode ter preenchido o vazio e satisfeito a necessidade de realização das 
fantasias do sujeito, assim sendo, não é mais necessário desenhar um ambiente com tantos detalhes, uma vez que seu mundo interno está preenchido pelo contato com o outro, no caso, o cão. Na comparação dos relatos, percebe-se que no discurso aparece o que é essencial. No primeiro relato, parece que tudo o que tem no quarto é importante, já no segundo, há uma redução na necessidade de preenchimento desse vazio.

WARTEGG - Pré IAA: Diluição do Eu e dificuldade para expor seus sentimentos. Necessidade de proteção e expansão interna. Ansiedade e angústia. Pós IAA: Integração do Eu. Dificuldade em expor seus sentimentos. Demonstra necessidade de segurança e agressividade diluída. Forte controle da agressividade. Pouca vitalidade e passividade. Comparação dos resultados: Tentativa de reintegração do Eu apesar da dificuldade em lidar e expor seus sentimentos. Diminuição de ansiedade e angústia.

SÍNTESE FINAL - Maior organização interna no desenho pós IAA coincide com a tentativa de reorganização do Eu e com redução da ansiedade e angústia. Sugere-se que há um preenchimento do vazio interno após a intervenção do cão que reflete na redução da ansiedade.

SUJEITO 05: Idade: 09 anos, 02 meses, diagnóstico: náusea e vômito.

DESENHO LIVRE - Pré IAA: Desenho sugere insegurança, inibição e baixa energia. Sentimentos de tristeza, medo, morte e negativismo presentes pela predominância da cor preta no traçado. Relato do sujeito após o desenho: "Fiz eu aqui, a TV, amarrei ao soro". Pós IAA: Sentimentos de medo, tristeza, morte e negativismo presentes. Tentativa de encontrar equilíbrio emocional e enfrentamento do conflito ao se autodesenhar em pé, de frente e no centro da folha. Relato do sujeito após o desenho: "Desenhei eu e onde to sentindo dor". Comparação dos resultados: Em ambos, o sujeito mostra-se com fortes sentimentos ligados à tristeza e negativismo, além de energia muito baixa. No $2^{\circ}$ desenho o sujeito conseguiu se desenhar em pé, enquanto no primeiro ele está invertido na folha, em tamanho excessivamente pequeno e amarrado ao soro. Essa mudança no posicionamento da autoimagem pode indicar 
uma tentativa de enfrentamento da situação vivida ainda que a expressão do sofrimento seja evidente. No relato do sujeito, antes e depois da IAA, percebe-se que a dor prevalece pela ausência de desejo de se comunicar.

WARTEGG - Pré IAA: Postura de defesa da própria individualidade frente ao meio e falta de confiança em si mesmo. Afetividade negativa em relação às pessoas. Pouco aprofundamento nos sentimentos. Necessidade de expansão interna e ansiedade. Dificuldade de expansão dos impulsos frente a obstáculos. Necessidade de proteção. Pós IAA: Tentativa de encontrar a centralidade do Eu, ego fragilizado. Predomínio da racionalidade sobre a afetividade com o outro. Tendência a se aprofundar nos conteúdos internos. Dificuldade de expansão dos impulsos frente a obstáculos. Necessidade de proteção. Comparação dos resultados: Tentativa de reintegração do Eu e de se aprofundar nos sentimentos, nas angústias. Diminuição da ansiedade.

SíNTESE FINAL - Tentativa de reintegração do Eu e de enfrentamento do conflito, ainda que permeados de baixa energia e negatividade perante a situação e nas relações. Maior contato com conteúdos internos ligados a sentimentos de angústia em ansiedade.

\section{DISCUSSÃO}

As limitações do presente trabalho ocorrem na medida em que se trata de estudos de caso que não se propõem a generalizações estatísticas e sim teóricas. Para que se possa ampliar os achados em termos de evidência científica, faz-se necessário um estudo com grupo controle.

Os desenhos pré IAA sugerem que os sujeitos percebem seus corpos em condição patológica associada à fragmentação do $E u$. Destaca-se que o sujeito 01 representa emblematicamente essa afirmação: desenha apenas seu rosto, mas omite o restante do corpo. 
Figura 1 - Antes da IAA: Racionalização, negação da condição patológica, perda de sentido

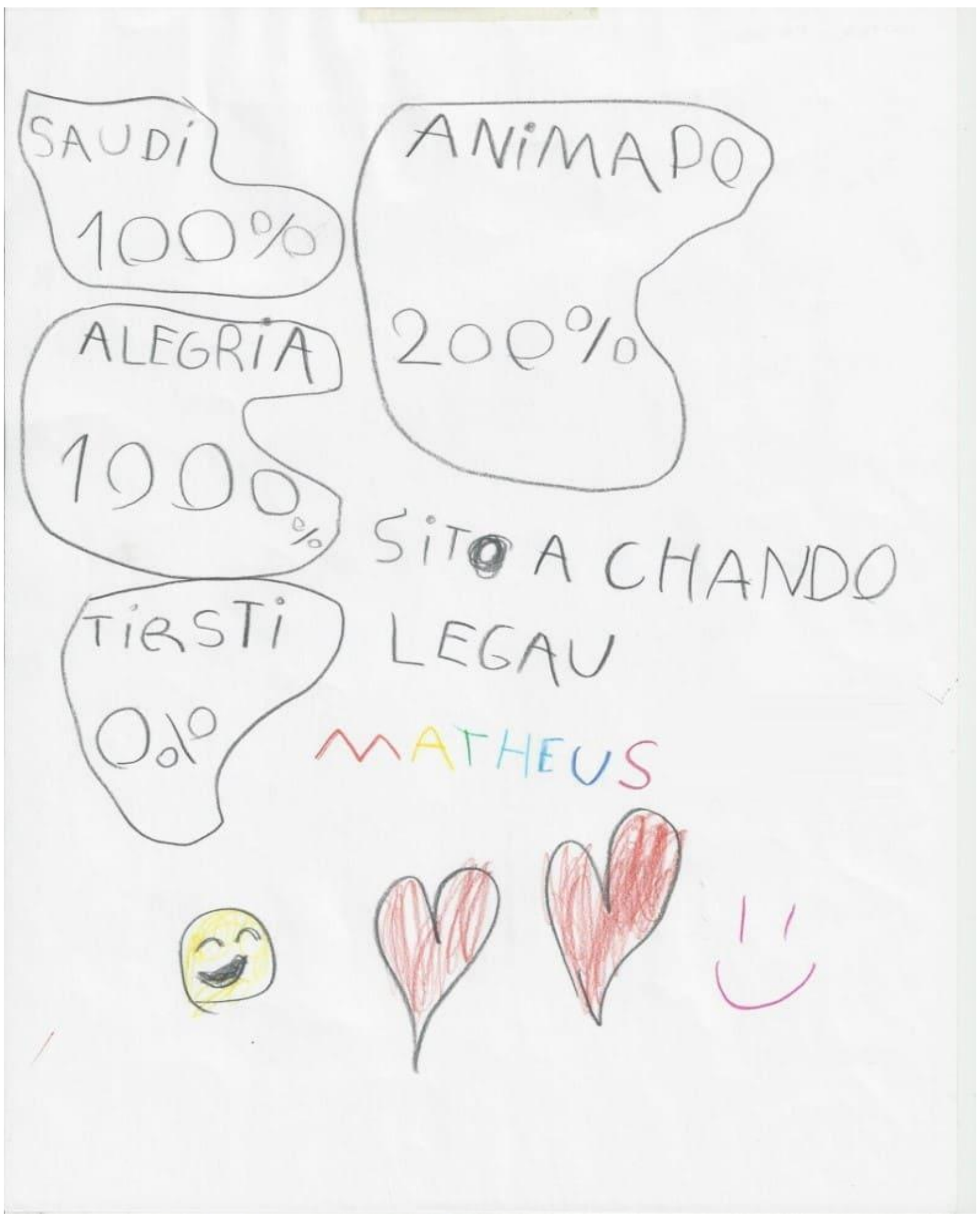


A propósito, a imagem do corpo é a síntese viva das experiências emocionais do sujeito, ou seja, ela é a representação simbólica inconsciente do Eu, vivida nas relações erógenas mais primitivas e atualizada nas relações presentes. Essa imagem pode ser expressa na linguagem por meio de desenhos, música, mímica e gestos, entre outros e tem como seu intérprete o esquema corporal que identifica o indivíduo enquanto espécie (DOLTO, 2002; MERÈDIEU, 1974).

Nesse sentido, observou-se nos desenhos e no teste de Wartegg pré IAA que todos os sujeitos manifestaram de alguma forma a patologização da imagem do corpo, coerente com aquele momento de vida. Os sujeitos 02,04 e 05 demonstraram em seus desenhos a experiência emocional da hospitalização, não só por se desenharem deitados no leito hospitalar, mas também pelos detalhes que os rodeiam. No desenho do sujeito 02, por exemplo, esses detalhes podem sugerir o sentimento de inadequação bem como um ambiente ameaçador, afinal, ele está rodeado de conteúdos inorgânicos como a seringa apontada em sua direção, o suporte de soro e uma cama desenhada com 06 pés, que pode ser interpretada como necessidade de forte sustentação do corpo doente.

O Eu fragmentado é evidenciado nos desenhos e teste de Wartegg pré IAA de todos, representado por sentimentos de negação, ansiedade, forte racionalização, sentimentos de constrição e inadequação ao ambiente e à própria noção da condição patológica. Nos sujeitos 01,02 e 03 os desenhos pré IAA sugerem que os aspectos racionais se sobrepõem aos emocionais uma vez que a escrita aparece inicialmente como expressão gráfica do sentir, corroborando a ideia de que os conteúdos manifestos podem operar como censura aos conteúdos latentes (SOUZA; PRIMI; MIGUEL, 2007). Embora esse processo tenha ocorrido, é interessante observar que para os 03 sujeitos houve a transição da escrita para o desenho, um retorno ao lúdico, sendo possível realizar uma análise dos aspectos emocionais mais profundos desses indivíduos.

Após a IAA observou-se redução do conteúdo racional, maior contato com a angústia e tentativas de reorganização interna, como demonstra o desenho do sujeito 01 que pôde expressar a autoimagem completa e interagindo com o cão, ressignificando 
simbolicamente sua imagem de corpo. Pode-se dizer que a esse sujeito foi possível, naquele momento, uma reintegração do $E u$, antes fragmentado, a partir da brincadeira com o cão. Cabe ressaltar aqui que a brincadeira é uma característica da saúde e faz parte do processo natural de crescimento, assim, pode-se dizer que durante a atividade com o cão, a criança pôde trazer à tona sua inclinação natural de brincar e, de alguma forma, se distanciar por alguns minutos da sua condição patológica (MITRE; GOMES, 2004).

Figura 2 - Depois da IAA - Contato com aspectos emocionais, reintegração da autoimagem, enfrentamento da doença

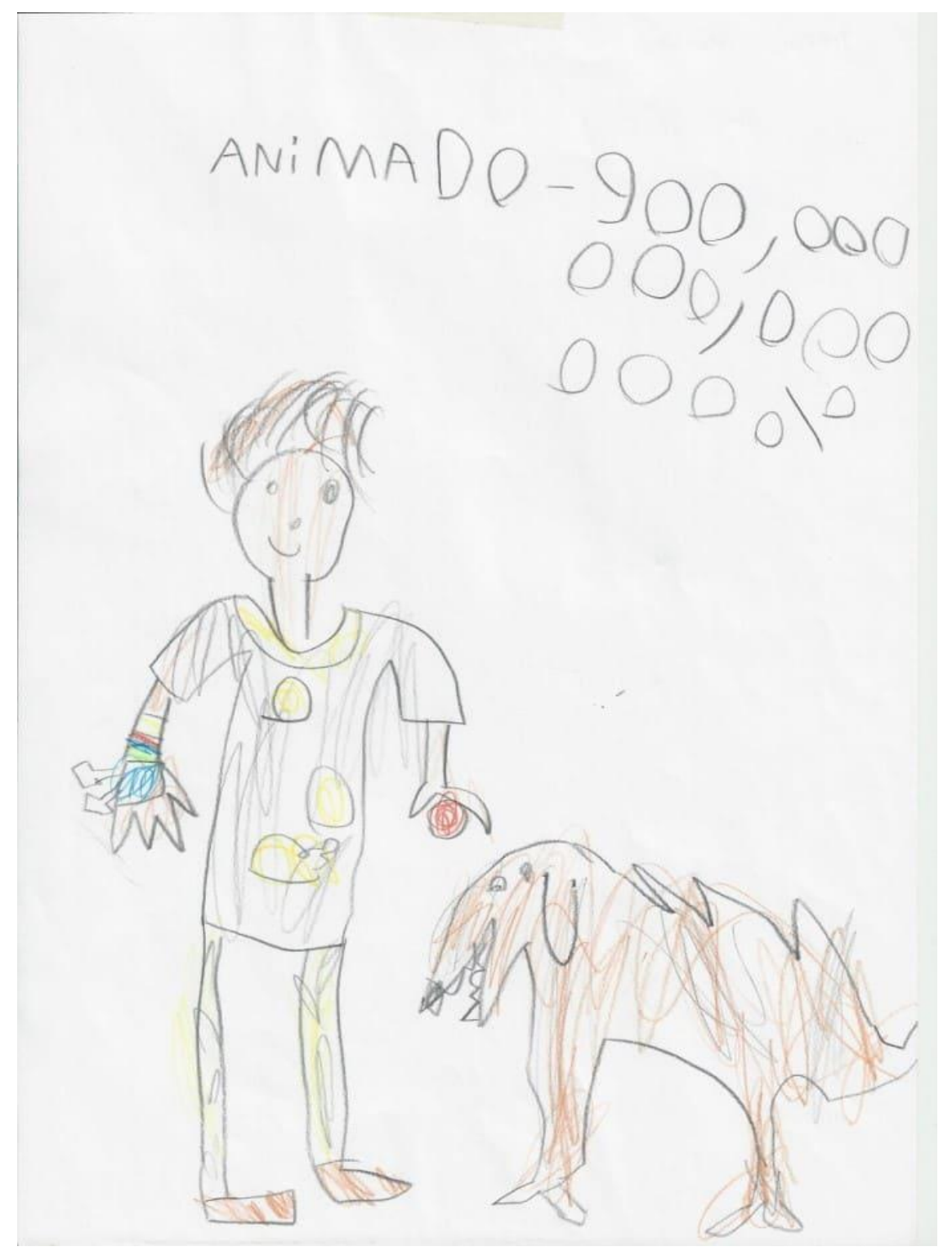


Com relação à ansiedade, a presença do animal no ambiente hospitalar reduz os níveis de stress e ansiedade em pacientes pediátricos, estimulando cuidados pessoais, contato com o outro e atividades físicas (CALCATERRA; VEGGIOTTI; PALESTRINI; et al., 2015). Nesse sentido, na comparação dos desenhos do sujeito 04, essa percepção também é evidente, onde há uma clara reorganização dos aspectos emocionais, redução da ansiedade e tentativa de enfrentamento do conflito relacionado à doença e hospitalização.

Observou-se que a presença do cão favoreceu a experiência de reintegração do Eu e de reorganização da imagem inconsciente do corpo. Nos casos dos sujeitos 03 e 04, pode-se identificar no campo 01 do teste de Wartegg que representa o ego e suas defesas que na aplicação pré IAA não houve contato com o estímulo que sugere sentimento de diluição, de fragmentação. $\mathrm{Na}$ aplicação pós IAA, ambos incluíram o estímulo em seus desenhos, sugerindo maior contato com a própria subjetividade e reorganização dessa imagem inconsciente do corpo.

Foi possível identificar também nos sujeitos 03 e 05 , um contato maior com a afetividade após a IAA: a presença do cão associou-se a alternativas criativas para lidar com o conflito e tentativas de reapropriação do Eu, representadas nos desenhos e, novamente, no primeiro campo do teste de Wartegg. Esse campo coloca o indivíduo emocionalmente de frente a si mesmo e nos mostra como ele se percebe e sua forma de enfrentar os problemas (SOUZA; PRIMI; MIGUEL, 2007). 


\section{Teste de Wartegg do sujeito 3}

\section{Antes da IAA}

Figura 3 - Campo 01: não houve contato com o estímulo, que sugere sentimentos de diluição e de fragmentação

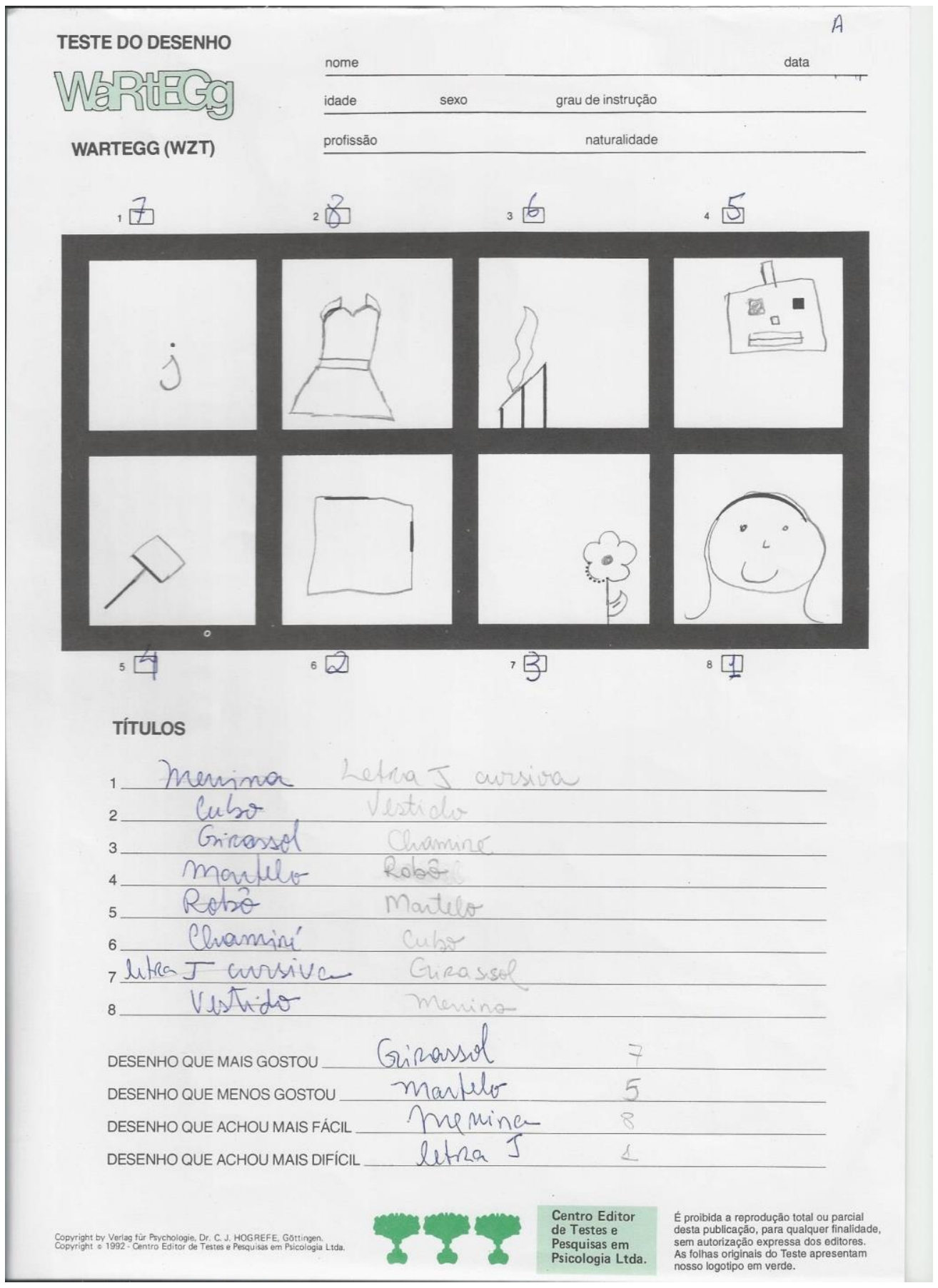


Depois da IAA

Figura 4 - Campo 01: sujeito incluiu o estímulo em seu desenho, sugerindo maior contato com a própria subjetividade e reorganização dessa imagem inconsciente do corpo

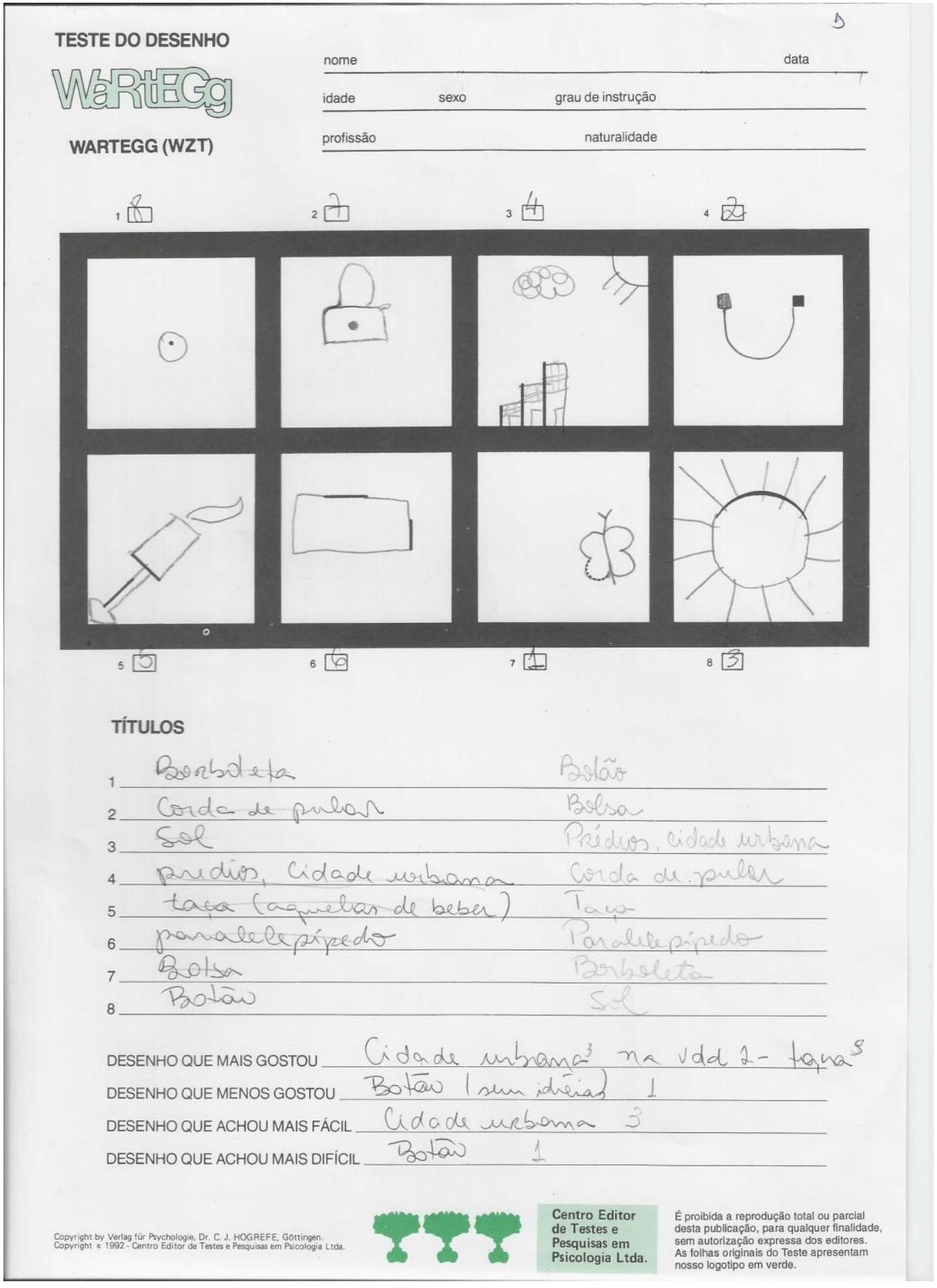

RC: 57470

Disponível em: https://www.nucleodoconhecimento.com.br/psicologia/criancas-hospitalizadas 
Diante dos resultados obtidos, cabe perguntar: o cão ocupou uma função de "cuidador" diferenciado dos sujeitos hospitalizados? A propósito, alguns aspectos podem ser elencados: a partir de uma abordagem que oferece ao paciente a opção de interagir com o animal, cria-se uma possibilidade de vínculo diferente daquele estabelecido com os profissionais que atuam no ambiente hospitalar, os quais o submetem aos procedimentos clínicos protocolares. Assim, Ihe é oferecida a opção de experimentar um relativo resgate da autonomia durante a IAA.

Nessa direção, a presença do cão tem caráter "despatologizante" já que a interação humano-animal é genuinamente lúdica e independe das manifestações sintomáticas (em termos orgânicos) em favor dos vínculos afetivos. Em outras palavras: o "olhar do cão" não discrimina indivíduos saudáveis e doentes.

No presente estudo, observou-se que o cão atuou como interlocutor que acolhe o brincar proposto pela criança sem objeções, favorecendo que ela reorganizasse seu $E u$ e encontrasse recursos internos para enfrentar as angústias geradas pela hospitalização. Ou seja, é possível sugerir que o cão ocupou o papel de cuidador, favorecendo transformações desejáveis à vivência angustiante da hospitalização.

Outro aspecto a ser observado é que, nessa relação de cuidados, é possível surgir uma inversão imaginária de papéis: a criança passa de objeto de cuidados a cuidador do cão. Explicitando: atividades lúdicas como escovar o animal, acariciá-lo, solicitar comandos de obediência, "dar injeções" no cão e "auscultar seu coração" configuraram um exercício criativo que potencializou o contato/elaboração/tolerância da sensação de angústia inerente à condição patológica. Cria-se, nessa inversão, uma forma eficaz de cuidado já que esse processo possibilita uma reversão de expectativas em que se reafirmam, simultaneamente, a subjetividade individual e o reconhecimento do outro (FIGUEIREDO, 2009; DELOUYA, 2010).

Nessa perspectiva, é importante observar que com todos os sujeitos, em algum momento da interação, essa inversão de papéis acontecia. E, nessa reversibilidade, as crianças puderam transformar a realidade de acordo com seus desejos, reorganizando sentimentos e percepções em termos intra-psíquicos (GREEN, 2013). 
Por fim, é importante sublinhar dois aspectos: em qualquer técnica projetiva as interpretações mostram tendências e não generalizações acerca da personalidade do indivíduo, esse estudo não estabelece uma relação de causalidade estrita entre as modificações operadas no psiquismo dos sujeitos e as IAA. Mas, os resultados nos permitem argumentar em favor de que a presença do cão favoreceu um enquadre potencialmente transformador.

\section{CONCLUSÃO}

Os resultados dessa pesquisa sugerem que, nos sujeitos estudados, a IAA em ambiente hospitalar proporcionou uma experiência de reintegração do $E u$, ou seja, uma reapropriação da identidade subjetiva, parcialmente tolhida pelo processo de adoecimento e hospitalização. Ou seja, a IAA promoveu maior contato com a afetividade e decorrente enfrentamento/elaboração de conteúdos psíquicos, em diferentes graus. No entanto, mais estudos se fazem necessários para avaliar as consequências psicológicas da interação entre crianças hospitalizadas e cães.

\section{REFERENCIAS}

BUSSOTTI, Edna Aparecida; LEAO, Eliseth Ribeiro; CHIMENTAO, Denise Maria Nasciment; SILVA, Cristiane Pavanello Rodrigues. Assistência Individualizada: "Posso trazer meu cachorro?". Revista da Escola de Enfermagem da USP, vol. 39, n. 2, pp. 195-201, 2005.

CALCATERRA, Valeria; VEGGIOTTI, Pierangelo; PALESTRINI, Clara; DE GIORGIS Valentina; RASCHETTI, Roberto; TUMMINNELLI, Massimiliano et al. Post-operative benefits of animal-assisted therapy in pediatric surgery: a randomized study. PLoS One, vol. 10, n. 6, 2015, e0125813.

CAMPOS, Dinah Martins de Souza. O teste do desenho como instrumento de diagnóstico da personalidade. Petrópoles (RJ): Vozes, 2000. 
CAPRILLI, Simona; MESSERI, Andrea. Animal-Assisted Activity at A. Meyer Children Hospital: A Pilot Study. Evidence-Based Complementary Alternative Medicine, vol. 3, n. 3, pp. 379-383, 2006.

COSTA, Tarsila Salvador; MORAIS, Aisiane Cedraz. A hospitalização infantil: vivência de crianças a partir de representações gráficas. Revista de Enfermagem UFPE on line, Pernambuco, vol. 11, Supl. 1, pp. 358-367, 2017.

DELOUYA, Daniel. Cuidar na clínica e na cultura. Revista Latinoamericana de Psicopatologia Fundamental, vol. 13, n. 2, pp. 356-360, 2010.

DOLTO, Françoise. A Imagem Inconsciente do Corpo. São Paulo: Perspectiva, 2002.

DOTTI, Jerson. Terapia e Animais. São Paulo: Livrus, 2005.

FIGUEIREDO, Luís Cláudio M. As Diversas Faces do Cuidar: Novos Ensaios de Psicanálise Contemporânea. São Paulo: Escuta, 2009.

GLENK, Lisa Maria; KOTHGASSNER, Oswald David; STETINA, Birgit Ursula; PALME, Rupert; KEPPLINGER, Berthold; BARAN, Halina. Salivary cortisol and behavior in therapy dogs durinho animal-assisted interventions: a pilot study. Journal of Veterinay Behavior, vol. 9, pp. 98-106, 2014.

GREEN, André. Brincar e Reflexão na Obra de Winnicott. São Paulo: Zagodini, 2013.

IAHAIO. IAHAIO White Paper, 2014. Disponível em: http://www.iahaio.org/new/fileuploads/4163IAHAIO WHITE PAPER- FINAL - NOV 242014.pdf. Acesso em 05/10/2016.

ICHITANI, Tatiane; CUNHA, Maria Claudia. Animal-assisted activity and pain sensation in hospitalized children and adolescents. Revista Dor, vol. 17, n. 4, pp. 270273, 2016. 
ICHITANI, Tatiane; CUNHA, Maria Claudia. Effects of animal-assisted activity on selfreported feelings of pain in hospitalized children and adolescents. Psicologia: Reflexão e Crítica, vol. 29, n. 43, 2016.

LAPLANCHE, Jean; PONTALIS, J-B. Vocabulário da Psicanálise, / Laplanche e Pontalis; sob a direção de Daniel Lagache; tradução Pedro Tamen. 4 Ed. São Paulo: Martins Fontes; 2001.

LEFEBVRE, Sandra L.; GOLAB, Gail C.; CHRISTENSEN, E'lise; CASTRODALE, Louisa; AUREDEN, Kathy; BIANCHOWSKI, Anne; et al. Guidelines for animalassisted interventions in heath care facilities. American Journal of Infection Control. 2008;36(2):78-85.

MERÈDIEU, Florence de. O desenho Infantil. São Paulo: Editora Cultrix, 1974.

MITRE, Rosa Maria de Araújo; GOMES, Romeu. A promoção do brincar no contexto da hospitalização infantil como ação de saúde. Ciência \& Saúde Coletiva, vol. 9, n. 1, pp. 147-154, 2004.

MORAES, Elissa Orlandi; ENUMO, Sônia Regina Fiorim. Estratégias de enfrentamento da hospitalização em crianças avaliadas por instrumento informatizado. Psico-USF, vol. 13, n. 2, pp. 221-231, 2008.

MOREIRA, Rebeca Lima; GUBERT, Fabiane do Amaral; SABINO, Gubertll, Leidiane Minervina Moraes de; BENEVIDES, Jéssica Lima; TOMÉ, Marcela Ariadne Braga Gomes; MARTINS, Mariana Cavalcante; et al. Terapia assistida com cães em pediatria oncológica: percepção de pais e enfermeiros. Revista Brasileira de Enfermagem, vol. 69, n. 6, pp. 1122-1128, 2016.

ODENDAAL, J. S.; MEINTJES, R. A. Neurophysiological correlates of affiliative behaviour between humans and dogs. The Veterinary Journal, vol. 165, n. 3, pp. 296 301, 2003. 
OLIVEIRA, Ana Maria Moreno de; SILVESTRO, Viviane Salete. O impacto emocional sofrido pelo escolar em processo de hospitalização. Akrópolis Umuarama, vol. 23, n. 2, pp. 15-27, 2015.

OLIVEIRA, Glícia Ribeiro; ICHITANI, Tatiane; CUNHA, Maria Claudia. Atividade Assistida por Animais: efeitos na comunicação e interação social em ambiente escolar. Revista Distúrbios da Comunicação, vol. 28, n. 4, pp. 759-763, 2016.

REED, Reiley; FERRES, Lilian; VILLEGAS, Natalia. Curadores naturais: uma revisão da terapia e atividades assistidas por animais como tratamento complementar de doenças crônicas. Revista Latino Americana de Enfermagem, vol. 20, n. 3, pp. 1-7, 2012.

SILVA, Cláudia da Costa; RIBEIRO, Nair Regina Ritter. Percepções da criança acerca do cuidado recebido durante a hospitalização. Revista Brasileira de Enfermagem, vol. 53, n. 2, pp. 311-323, 2000.

SILVEIRA, Isa Rodrigues; SANTOS, Nanci Cristiano; LINHARES, Daniela Ribeiro. Protocolo do programa de assistência auxiliada por animais no hospital universitário. Revista da Escola de Enfermagem da USP, vol. 45, n. 1, pp. 283-288, 2011.

SOUZA, Carmen Vera Rodrigues de; PRIMI, Ricardo; MIGUEL, Fabiano Koich. Validade do teste Wartegg: correlação com 16PF, BPR-5 e desempenho profissional. Avaliação Psicológica, vol. 6, n. 1, pp. 39-49, 2007.

VAGNOLI, Laura; CAPRILLI, Simona; VERNUCCI, Chiara; ZAGNI, Silvia; MUGNAI, Francesca; MESSERI, Andrea. Can presence of a dog reduce pain and distress in children during venipuncture?. Pain Management Nursing, vol. 16, n. 2, pp. 89-95, 2015.

VASQUES, Raquel Candido Ylamas; BOUSSO, Regina Szylit; MENDES-CASTILLO, Ana Márcia Chiaradia. A experiência de sofrimento: histórias narradas pela criança hospitalizada. Revista da Escola de Enfermagem da USP, vol. 45, n. 1, pp. 122-129, 2011. 
WARTEGG, Ehrig. Teste de Wartegg, WTZ: diagnóstico de camadas: livros I e II. São Paulo: Casa do Psicólogo, 1987.

Enviado: Maio, 2020.

Aprovado: Agosto, 2020. 